\title{
The effects of temperature and ultrasound on the migration of di-(2-ethylhexyl) phthalate from plastic packaging into dairy products

\author{
${ }^{1}$ University of Niš, Faculty of Sciences and Mathematics, Višegradska 33, 18000 Niš, Serbia \\ ${ }^{2}$ University of Niš, Faculty of Medicine, Bulevar dr Zorana Đinđića 81, 18000 Niš, Serbia
} \\ D. S. Bogdanović ${ }^{*}$, D. H. Anđelković ${ }^{1}$, I. S. Kostić ${ }^{1}$, G. M. Kocić ${ }^{2}$, T. D. Anđelković ${ }^{1}$
}

Received, December 13, 2018; Revised, January 22, 2019

The aim of this paper is to define migration of phthalates from plastic packaging into dairy products of different fat content caused by increasing temperature and application of ultrasound on dairy product. The most common used phthalate, di-(2-ethylhexyl) phthalate (DEHP) was investigated for migration into following food-recipients with different fat content: infant formula, milk powder, whey powder and water. The results obtained by liquid-liquid extraction followed by gas chromatography-mass spectrometry (GC-MS) were compared. The base peak ion of DEHP $(\mathrm{m} / \mathrm{z}, 149)$ was selected for further research and recording was performed in the selected ion monitoring mode (SIM). For the considered range of phthalate concentrations, $0.25-2.50 \mu \mathrm{g} \mathrm{mL} \mathrm{m}^{-1}$, the response of the mass-selective detector (MSD) was linear. Results showed that the migration of DEHP from packaging material is higher in dairy products with higher percentage of fat. The mass of migrated DEHP was the highest in the sample of infant formula, followed by powdered milk, whey powder and water. Phthalates being just incorporated into plastics, and not chemically bound to plastics, show increased migration when ultrasound is applied in addition to increased temperature.

Keywords: phthalate; milk samples; leachability; gas chromatography-mass spectrometry.

\section{INTRODUCTION}

Phthalates are organic chemical compounds that make up the basic component of all plastic packaging to make it more flexible, more elastic and softer to use and for that reason they are also called plasticizers. The proportion of phthalate in a plastic product can be up to $45 \%$ of its total weight, depending on the type and purpose of the product itself [1-3]. The most commonly used phthalates are dimethyl phthalate (DMP), dibutyl phthalate (DBP), butyl benzyl phthalate (BBP), di(2-ethylhexyl) phthalate (DEHP), di- $n$-octyl phthalate (DOP), diisononyl phthalate (DINP), diisodecyl phthalate (DIDP). Although there is a large number of phthalates, only some of them are produced massively, at industrial level, such as the production of DEHP (50\% of the total annual production of phthalates belongs to the production of DEHP). The World Health Organization (WHO) estimated that the annual industrial production of phthalate approached the amount of 8 million tons [4]. Long-chain phthalates or high molecular weight ones, such as DEHP, are mainly found in flexible polyvinyl chloride materials (PVC) used in consumer products such as food packaging and medical equipment (peritoneal dialysis bags and tubing, intravenous bags, infusion tubing, blood bags, catheters, oxygen masks, etc.) [5-6].

Because of their physical and chemical properties, phthalates are very mobile and easily

\footnotetext{
* To whom all correspondence should be sent:

E-mail: dannica.milojkovic@gmail.com
}

migrate from plastic products to the surrounding environment. Phthalates are just incorporated into plastics; they are not chemically bound to the plastic material, which causes their ability to subsequently leach out [7]. Small amounts of fatty foods, oils or dairy products are enough for almost complete extraction of these lipophilic softeners and migration into food. Due to the large use of these plasticizers, exposure to humans is inevitable. People can be exposed to phthalates in several ways: dermal, inhalation, oral, intravenous, while the highest exposure takes place through ingestion of contaminated food. A study in Canada estimates that a man (20-70 years) of an average body weight of $70 \mathrm{~kg}$ receives most phthalates via food (4900 ng of DEHP kg-1 body weight / day) [8]. The estimated total daily exposure of humans to DEHP is $5800 \mathrm{ng}$ $\mathrm{kg}^{-1}$ body weight / day.

Considering that phthalates affect human health [9-12] and that phthalates are found in more than 95 $\%$ of human urine samples worldwide by biomonitoring studies, the European Food Safety Authority (EFSA) lists the tolerable daily intake values (TDI) for phthalates. The TDI values for DBP, DEHP and BBP are 10, 50 and $500 \mu \mathrm{g} \mathrm{kg}^{-1}$ body weight / day, respectively [13]. For DINP and DIDP, TDI amount is $150 \mu \mathrm{g} \mathrm{kg}^{-1}$ body weight / day [14].

In this study, whey powder, powdered milk and infant formula were used, as a food that is very important in the nutrition of infants, children, athletes and sick people. Milk powder that contains 
$2-3 \%$ of water is a very long-lasting milk product that has great application in the diet of people, especially children. Whey powder is a product of cheese production that represents a source of important minerals and proteins. Infant formula is a milk product suitable for feeding babies since their birth and for this reason it is crucial that it does not comprise contaminants (e.g. phthalates). The migration of DEHP into water was also examined in order to compare DEHP leachability into a polar matrix without fat with its leachability into dairy products of different fat content.

Previous experiments showed that phthalates migration from packaging materials is influenced by storage time, storage temperature, exposure to heat / light, $\mathrm{pH}$ of the sample, PET bottle volume [15-17]. However, according to the detailed literature search, this is the first systematic report that investigates the influence of temperature and ultrasound on the migration of DEHP from plastic material into dairy products. In this paper, the ultrasound-assisted migration with influence of temperature was tested. It was also examined how the composition of dairy products (fat content) influenced the degree of the migration of DEHP. As high-level phthalate source for this investigation a dialysis bag was used with predefined content of DEHP [18].

\section{EXPERIMENTAL}

\section{Reagents and materials}

HPLC grade $n$-hexane was purchased from Sigma-Aldrich (St. Louis, MO, USA). Di(2ethylhexyl) phthalate (DEHP) was purchased, in the highest available purity, from Sigma-Aldrich (St. Louis, MO, USA). Dibutyl adipate (DBA) was purchased from Fluka (Buchs, Switzerland) and used as an internal standard. Water from a Milli-Q system (Millipore, Bedford, MA, USA) was used. Dialysis bag (Baxter, USA) was used. Milk powder was purchased from Gold pack (Serbia), whey powder was from Madico (Poland) and infant formula was purchased from Humana (Germany).

In order to minimize the contamination by phthalates from the laboratory, only glassware equipment was used. All glassware was washed with soap, tap water and ultrapure water, then washed with acetone and $n$-hexane and dried at 200 ${ }^{\circ} \mathrm{C}$ in the oven for 4 hours [19].

All stock, intermediate and working solutions were prepared in $n$-hexane. The stock solutions of DEHP and DBA were prepared at a concentration of $1.0 \mathrm{mg} \mathrm{mL}$. The stock standard was diluted stepwise with $n$-hexane to prepare working solutions of DEHP. The calibration standard series was obtained with DEHP in the concentration range of $0.25,0.50,1.00,1.50$ and $2.50 \mu \mathrm{g} \mathrm{mL}^{-1}$ with DBA as the internal standard, at a concentration of $1 \mu \mathrm{g} \mathrm{mL}^{-1}$. The calibration curve was linear in the range from 0.25 to $2.5 \mu \mathrm{g} \mathrm{mL}^{-1}$ with a correlation coefficient higher than 0.99 . The linear dynamic range was broader and covered the range from 2.50 to $50 \mu \mathrm{g} \mathrm{mL}^{-1}$.

\section{GC-MS analysis}

Determination of DEHP was performed on a gas chromatograph 6890 (Hewlett-Packard) equipped with a mass selective detector (MSD) 5973 (Agilent, USA) and a DB-5 MS capillary column $(30 \mathrm{~m} \times 250 \mathrm{~mm} \times 0.25 \mathrm{~mm})$ (Agilent, USA). The gas chromatograph was operated in the splitless injection mode. The oven temperature was programmed from $60{ }^{\circ} \mathrm{C}(1 \mathrm{~min})$ to $220^{\circ} \mathrm{C}(1 \mathrm{~min})$ at a rate of $20^{\circ} \mathrm{C} \mathrm{min}-1$ and then to $280{ }^{\circ} \mathrm{C}(4 \mathrm{~min})$ at a rate of $5{ }^{\circ} \mathrm{C} \mathrm{min}{ }^{-1}$. Helium was the carrier gas $\left(1.0 \mathrm{~mL} \mathrm{~min}^{-1}\right)$ and the inlet temperature was 250 ${ }^{\circ} \mathrm{C}$. The operating temperature of the MSD was 280 ${ }^{\circ} \mathrm{C}$ with the electronic impact of $70 \mathrm{eV}$. The dwell time was $100 \mathrm{~ms}$. The MSD was used in the single ion-monitoring mode (SIM) at $m / z$ 149. The identification and quantification of the target compound was based on the relative retention time, the presence of target ions and its relative abundance. The quantification ion is $\mathrm{m} / \mathrm{z} 149$ for DEHP and ion $m / z \quad 185$ was chosen as representative ion of DBA internal standard.

\section{Samples preparation}

In order to test the degree of migration of DEHP from the plastic material under the influence of temperature and ultrasound, the following dairy products were used: milk powder, whey powder, infant formula. Water was taken for comparison as a phthalate recipient of high polarity and no fat content. Nutritional values of milk powder, whey powder and infant formula are given in Table 1.

Preparation of milk samples was done according to the producer's instruction. Water from a Milli-Q system was used to prepare the solutions of dairy samples. Milk powder (45 g), powdered whey (65 g) and infant formula (45 g) were dissolved in $1 \mathrm{~L}$ of water, respectively. Fresh samples of dairy products were prepared immediately before analysis. 
D. S. Bogdanović et al.: The effects of temperature and ultrasound on the migration of di-(2-ethylhexyl) phthalate ...

Table 1. Nutritional values of infant formula, milk powder and whey powder

\begin{tabular}{cccc}
\hline & Fats $(\%)$ & Lactose $(\%)$ & Milk proteins $(\%)$ \\
\hline Infant formula & 22.8 & 39.0 & 10.1 \\
Milk powder & 20.0 & 55.0 & 9.0 \\
Whey powder & 2.0 & 61.0 & 11.0 \\
\hline
\end{tabular}

A dialysis bag with a known content of DEHP was used to examine phthalate migration, as a reliable source of phthalate. The used dialysis bag contains about $35.8 \%$ of DEHP compared to the total weight [18]. Sample of the dialysis bag was measured to provide the same weight-to-volume ratio of dialysis bag and the sample of diary product, as if the dairy product was kept in the dialysis bag.

The exactly weighed dialysis bag was cut into pieces of $1 \mathrm{~cm}^{2}$ and added into $35 \mathrm{~mL}$ of dairy samples. The conditions for migration tests were set in two ways: (1) for determination of effects of exposure time and temperature heating up to $60{ }^{\circ} \mathrm{C}$ for up to $60 \mathrm{~min}$ with total heating time up to 60 hours was applied; (2) determination of effects of ultrasound-assisted migration was applied whenever heating was applied.

The influence of temperature was investigated as follows: samples were vigorously stirred and heated to a temperature up to $60{ }^{\circ} \mathrm{C}$ for $60 \mathrm{~min}$. After heating, the samples were left to cool at room temperature and filtered into vessels of $50 \mathrm{~mL} . n$ Hexane $(20 \mathrm{~mL})$ was added to the samples. The method of extraction of DEHP from dairy samples by $n$-hexane was shown to be a simple and effective procedure [20]. Manual shaking for $15 \mathrm{~min}$ and extraction agitation on the ultrasonic bath for 30 min were done. Blurred extracts were left for clarification. After separation of layers, the hexane layer was concentrated to a volume of $1 \mathrm{~mL}$. DBA was added to the evaporated hexane extract so that the concentration of DBA was $1 \mu \mathrm{g} \mathrm{mL}^{-1}$ and immediately analyzed by GC-MS. Pieces of dialysis bag were subjected to repeated migration tests into dairy products, providing a total heating time of $60 \mathrm{~h}$. The test was performed until a plateau was reached on the curve $m=f(t)$, where $m$ is mass of the migrated DEHP and $t$ is time.

The effect of ultrasound-assisted migration was studied in the same way as for temperature investigation with additional agitation that was performed on an ultrasonic bath.

All analyses were performed in triplicate and GC-MS quantification was repeated twice. The laboratory contamination was monitored with blank samples obtained from dairy samples without plastic pieces that were treated in the same way as the dairy samples with plastic pieces from the dialysis bag.

\section{RESULTS AND DISCUSSION}

\section{GC-MS acquisition}

The chromatogram of a standard solution of DEHP and DBA at a concentration of $2.5 \mu \mathrm{g} \mathrm{mL}^{-1}$ and $1.00 \mu \mathrm{g} \mathrm{mL}^{-1}$, respectively, is given in Fig. 1. The chromatogram shows that the separation of DEHP and DBA as internal standard, occurred within a running time of $20 \mathrm{~min}$ and retention times for DBA and DEHP were 9.990 and 18.426 min, respectively.

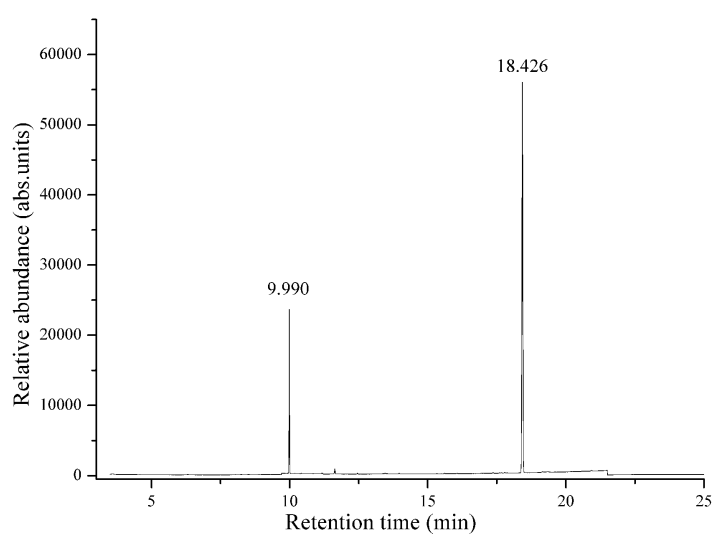

Fig. 1. GC-MS chromatogram of a standard solution of DEHP and DBA at concentrations of $2.5 \mu \mathrm{g} \mathrm{mL} \mathrm{m}^{-1}$ and $1.00 \mu \mathrm{g} \mathrm{mL} \mathrm{mL}^{-1}$, respectively.

The analytical curve obtained for DEHP within the concentration range $0.25-2.5 \mu \mathrm{g} \mathrm{mL}^{-1}$ is linear with a correlation coefficient $\mathrm{R}^{2}=0.99$ and linear equation $\mathrm{y}=(505228 \pm 9612) \mathrm{x}-(8473 \pm 13465)$, as shown on Fig. 2. The limit of determination (LOD) and limit of quantification (LOQ) were calculated from the signal/noise ratios which were multiplied with the factor 3 and 10 , respectively [21]. The LOD and LOQ values for DEHP are 0.04 $\mu \mathrm{g} \mathrm{mL} \mathrm{m}^{-1}$ and $0.12 \mu \mathrm{g} \mathrm{mL} \mathrm{mL}^{-1}$, respectively, with relative standard deviation (RSD) value of $3.6 \%$ (n $=3$ ).

Comparison of dairy products as recipients of DEHP and evaluation of influence of temperature and ultrasound on the migration of DEHP

The aim of this work is to determine the total mass of the migrated DEHP from plastic dialysis bag into recipient after repeated migration, related to temperature and ultrasound. 


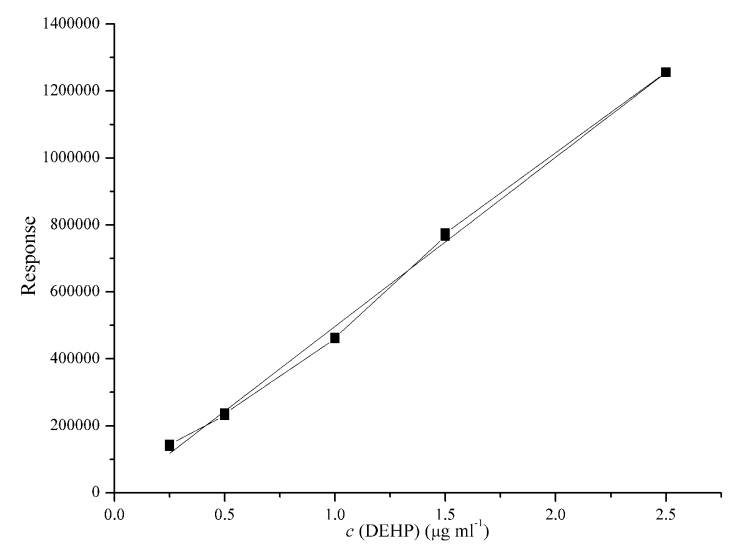

Fig. 2. The analytical curve for DEHP within the concentration range $0.25-2.5 \mu \mathrm{g} \mathrm{mL}^{-1}$

The initial phthalate concentrations were below detection limits in the samples of infant formula, milk powder, whey powder and water. The effects of exposure time, temperature, ultrasound and fat content of dairy products on the release of DEHP are summarized in Table 2.

The highest percentage of migrated DEHP was found in infant formula, which is associated with the fact that infant formula contains the highest percentage of fat $(22.8 \%)$, followed by milk powder (with a percentage of fat of $20 \%$ ), whey powder (with a fat content of $2 \%$ ) and water (without fat). The same trend is observed in both condition sets, for elevated temperature and for ultrasound-assisted migration, as shown in Fig. 3, with indication that ultrasound-assisted migration had a greater effect on the migration of DEHP.
Figures 4 and 5 show the graphs of the mass of the migrated DEHP as a function of exposure time.

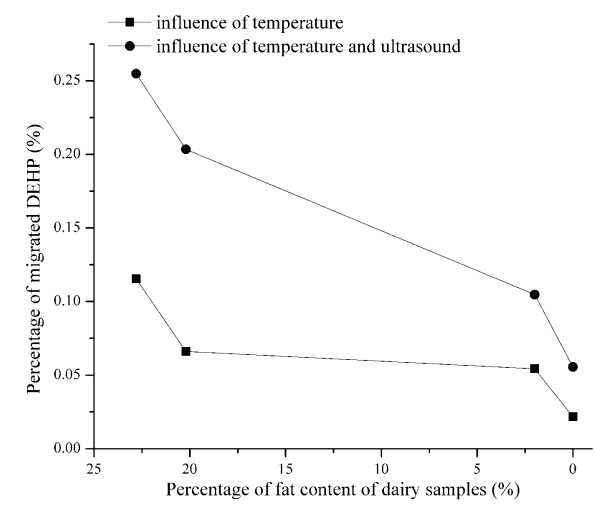

Fig. 3. The effects of temperature, ultrasoundassisted migration and fat content of dairy products on DEHP migration.

The graphs show a linear increase of the mass of migrated DEHP over time under the influence of temperature and ultrasound, until the plateau is reached. Plateau indicates that the maximum migration of DEHP has been achieved and DEHP no longer migrates into the samples under the given influence.

Maximal amount of migrated DEHP to water as recipient was reached after $1450 \mathrm{~min}$ due to the combined effect of elevated temperature and ultrasound and $2500 \mathrm{~min}$ by the effect of elevated temperature alone. Plateau was reached almost 1000 min faster in the case when ultrasound was applied beside temperature.

Table 2. Migration of DEHP influenced by (1) temperature and (2) ultrasound into recipients with different fat content

\begin{tabular}{lccccc}
\hline $\begin{array}{c}\text { Food } \\
\text { recipient } \\
\text { type }\end{array}$ & $\begin{array}{c}\text { Mass of part } \\
\text { of dialysis } \\
\text { bag }(\mathrm{g})\end{array}$ & $\begin{array}{c}\text { Mass of DEHP in } \\
\text { part of dialysis } \\
\text { bag }(\mathrm{g})^{19}\end{array}$ & $\begin{array}{c}\text { Total migration } \\
\text { time of DEHP } \\
(\mathrm{min})\end{array}$ & $\begin{array}{c}\text { Mass of } \\
\text { migrated } \\
\text { DEHP }(\mu \mathrm{g})\end{array}$ & $\begin{array}{c}\text { Percentage } \\
\text { of migrated } \\
\text { DEHP }(\%)\end{array}$ \\
\hline $\begin{array}{l}\text { Water } \\
\text { Whey }\end{array}$ & 1.7410 & 0.6233 & 2500 & $135.67 \pm 1.23$ & 0.02 \\
powder & 1.6113 & 0.5768 & 2950 & $311.83 \pm 1.40$ & 0.05 \\
Milk & 1.6200 & 0.5800 & 2900 & $384.66 \pm 3.61$ & 0.07 \\
$\begin{array}{l}\text { powder } \\
\text { Infant } \\
\text { formula }\end{array}$ & 1.4560 & 0.5212 & 3000 & $601.29 \pm 2.73$ & 0.12 \\
\hline $\begin{array}{l}\text { Water } \\
\text { Whey } \\
\text { powder }\end{array}$ & 1.4709 & 0.5266 & 1450 & $292.16 \pm 1.37$ & 0.06 \\
Milk & 1.4924 & 0.5343 & 2700 & $559.45 \pm 0.78$ & 0.10 \\
powder & 1.6049 & 0.5745 & 2800 & $1170.33 \pm 1.96$ & 0.20 \\
$\begin{array}{l}\text { Infant } \\
\text { formula }\end{array}$ & 1.4502 & 0.5192 & 2700 & $1323.36 \pm 1.87$ & 0.25 \\
\hline
\end{tabular}


D. S. Bogdanović et al.: The effects of temperature and ultrasound on the migration of di-(2-ethylhexyl) phthalate ...
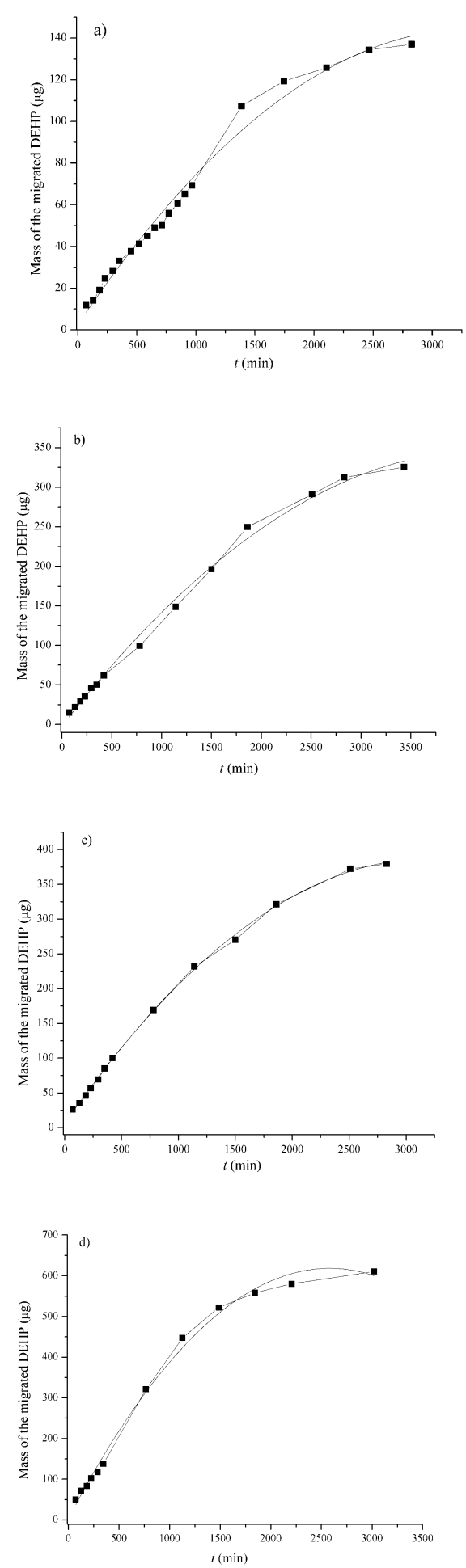

Fig. 4. The influence of temperature on the migration of DEHP in a) water, b) whey powder, c) milk powder and d) infant formula.

The time to achieve saturation, when ultrasound was applied, was shorter than when only temperature was applied for about $200 \mathrm{~min}$ for whey powder, milk powder and infant formula as recipients.
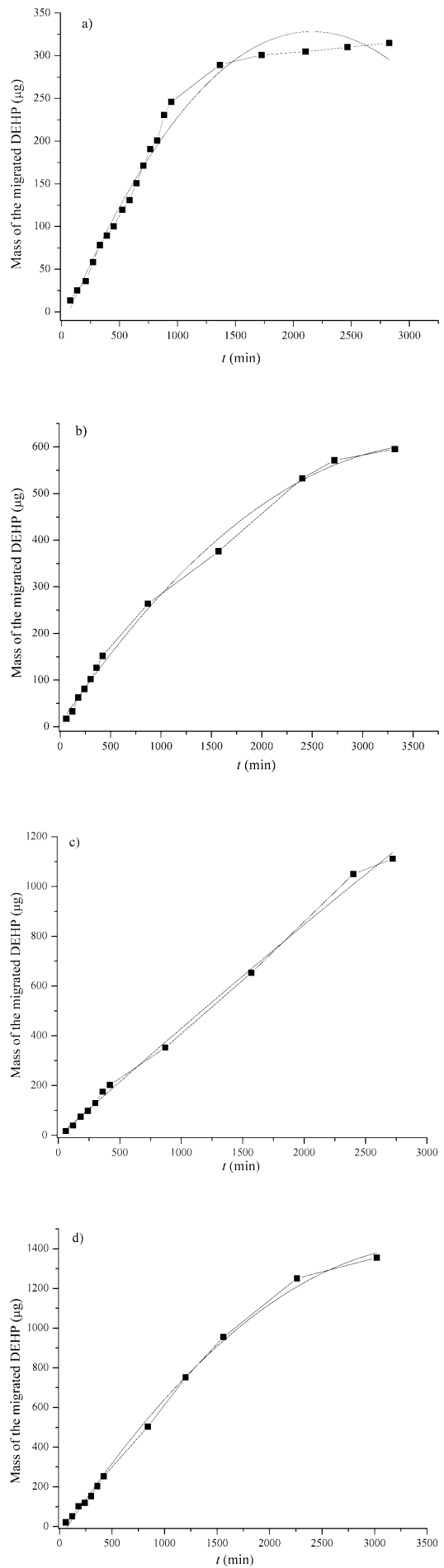

Fig. 5. The influence of ultrasound and temperature on the migration of DEHP in a) water, b) whey powder, c) milk powder and d) infant formula.

Expected reason is that water, as polar molecule, only "washed" molecules of DEHP from the plastic surface. On the other hand, non-polar milk samples can dissolve DEHP from the whole plastic material and for this a longer period is necessary.

Figures 6 and 7 show two time regions, one up to $450 \mathrm{~min}$ with a higher slope of the curve of 
migrated DEHP over time and the other from 450 up to 3500 min with a smaller slope. The graphs in (a) show the dependence of the mass of the migrated DEHP as a function of the total time of exposure of the samples to the effect of temperature and ultrasound and the graphs in (b) show the dependence of the mass of migrated DEHP in the first $450 \mathrm{~min}$. It is interesting to note that in the first $450 \mathrm{~min}$ the correlation between mass of migrated DEHP and time of extraction is almost linear, and the result is similar under both influences. This period is one sixth part of the total exposure time, and during this period about $30 \%$ of the total amount of migrated DEHP migrates into the recipients (Table 3). This migration was expressed, unlike the rest of the migration that takes place slower, until saturation is achieved.

It is interesting to note that in the first $450 \mathrm{~min}$ the correlation between mass of migrated DEHP and time of extraction is almost linear and the result is similar under both influences (Figs. 6 and 7). In this time period about $30 \%$ of the total migrated amount of DEHP migrates into the recipients (Table 3).

Obtained results showed that ultrasound has a greater effect on DEHP migration from the dialysis bag than temperature. Taking any time period during which the migration of DEHP from the dialysis bag was performed under both influences, a higher mass of DEHP was always obtained, under the influence of ultrasound, as can be seen in Table 3 , as in the graphs (Figs. 6 and 7). The degree of migration of DEHP under the influence of ultrasound increased by $223.34 \%$ for milk powder, by $128.79 \%$ for infant formula, by $92.93 \%$ for water and by $84.65 \%$ for whey powder. Increased efficiency of migration of DEHP due to the effect of ultrasound is a consequence of the power and energy provided by oscillations produced by ultrasound. In this way, the plastic pieces of the dialysis bag come in better contact with the sample; the sample under the influence of the energy of the ultrasound infiltrates deeper into the plastic, and soils DEHP in a larger quantity.
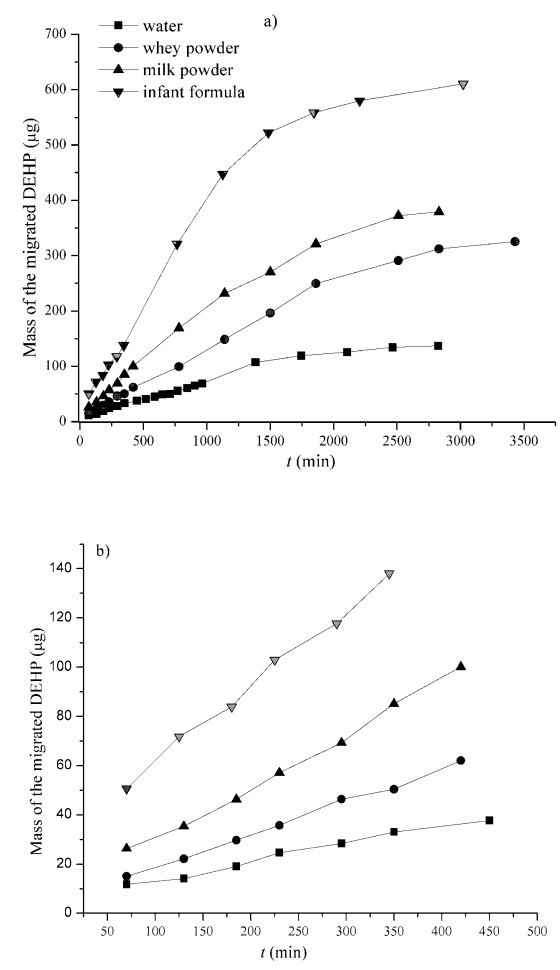

Fig. 6. Mass of the migrated DEHP under the influence of temperature a) in a time period of $3500 \mathrm{~min}$ and $b$ ) in a time period of $450 \mathrm{~min}$.
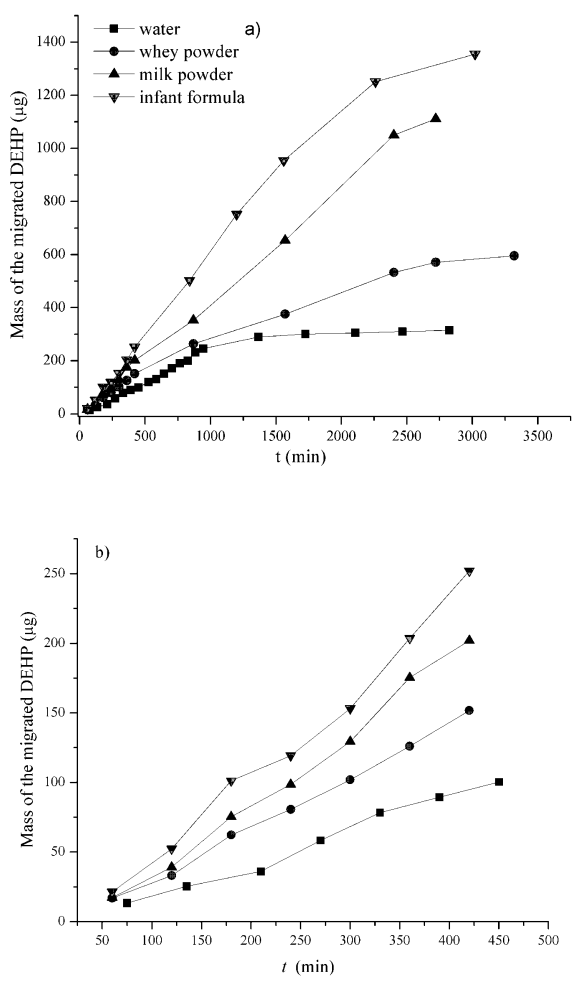

Fig. 7. Mass of the migrated DEHP under the influence of ultrasound a) in a time period of $3500 \mathrm{~min}$ and $b$ ) in a time period of $450 \mathrm{~min}$. 
D. S. Bogdanović et al.: The effects of temperature and ultrasound on the migration of di-(2-ethylhexyl) phthalate ... Table 3. Mass of migrated DEHP under the influence of temperature and ultrasound for different time periods

\begin{tabular}{|c|c|c|c|c|}
\hline & \multicolumn{4}{|c|}{ Mass of the migrated DEHP $(\mu \mathrm{g})$} \\
\hline & \multicolumn{2}{|c|}{$\begin{array}{l}\text { Under the influence of temperature } \\
\text { after a period of }\end{array}$} & \multicolumn{2}{|c|}{$\begin{array}{l}\text { Under the influence of temperature and } \\
\text { ultrasound after a period of }\end{array}$} \\
\hline & $450 \mathrm{~min}$ & $3000 \mathrm{~min}$ & $450 \mathrm{~min}$ & $3000 \mathrm{~min}$ \\
\hline Water & $38.55 \pm 0.79$ & $144.19 \pm 1.85$ & $110.34 \pm 0.99$ & $275.25 \pm 1.09$ \\
\hline \multicolumn{5}{|l|}{ Whey powder } \\
\hline & $67.67 \pm 1.56$ & $315.52 \pm 0.83$ & $142.29 \pm 1.06$ & $582.58 \pm 0.52$ \\
\hline Milk powder & $104.63 \pm 0.86$ & $385.43 \pm 0.96$ & $193.48 \pm 1.03$ & $1247.06 \pm 1.01$ \\
\hline Infant formula & $199.12 \pm 0.61$ & $601.41 \pm 1.08$ & $283.57 \pm 0.51$ & $1376.56 \pm 0.51$ \\
\hline
\end{tabular}

\section{CONCLUSIONS}

Obtained data for the migration of DEHP from packaging material to dairy products due to the effects of temperature, ultrasound and fat content of the dairy product show that migration depends on all three factors. The analysis has shown that in both cases when temperature and ultrasound were applied, the amount of migrated DEHP decreased in the following order: infant formula $>$ powdered milk > whey powder $>$ water, indicating that the fat content affects migration, the highest migration being observed for the dairy product with the highest fat content. By comparing the effects of temperature and ultrasound, the conclusion is that the influence of ultrasound on the migration of DEHP from plastic packaging into dairy products is higher than the effect of temperature, for all dairy products, due to the fact that ultrasound disrupts the structure of plastic material and accelerates diffusion and release of phthalate.

Acknowledgement: This study was supported by the Ministry of Education, Science and Technological Development of the Republic of Serbia and was performed as a part of Project TR 31060 .

\section{REFERENCES}

1. D. N. Brookle, S. Dobson, P.D. Howe, J.R. Nielsen, Environmental hazard assessment: di-(2-ethylhexyl) phthalate, United Kingdom Department of the Environment, Toxic Substances Division, Report TSD/2, London, 1991.

2. World Health Organization: Guidelines for Drinking-water Quality, 2008.

3. K. Bouma, D.J. Schakel, Food Addit. Contam. 19, 602 (2002).

4. T. Wenzl, Methods for the determination of phthalates in food, European Commission Joint
Research Centre, Institute for Reference Materials and Measurements, 2009.

5. X-L. Cao, Compr. Rev. Food. Sci. F. 9, 21 (2010).

6. M. Wormuth, M. Scheringer, M. Vollenweider, K. Hungerbuhler, Risk Anal., 26, 803 (2006).

7. HAH - Hrvatska agencija za hranu: Znanstveno mišljenje o prisutnosti ftalata u hrani, Osijek, 2014.

8. M.E. Meek, P.K.L. Chan, Environ. Carcinog. Ecotoxicol., 12, 179 (1994).

9. H.M. Koch, A.M. Calafat, Philos. Trans. R. Soc. Lond. Ser. B. Biol. Sci., 364, 2063 (2009).

10. I.K. Mahood, H.M. Scott, R. Brown, N. Hallmark, M. Walker, R.M. Sharpe, Environ. Health Perspect., 115, 55 (2007).

11. S.M. Duty, M.J. Silva, D.B. Barr, J.W. Brock, L. Ryan, Z. Chen, Epidemiology, 14, 269 (2003).

12. B.A. Johnsson, J. Richthoff, L. Rylander, A. Giwercman, L. Hagmar, Epidemiology, 16, 487 (2005).

13. European Food Safety Authority, EFSA J. 241, 1 (2005).

14. European Food Safety Authority, EFSA J. 243, 1 (2005)

15. V.G. Mihucz, G. Záray, Appl. Spectrosc. Rev., 51, 183 (2016).

16. M. Farhoodi, Z. Emam-Djomeh, M. Reza Ehsani, A. Oromiehie, Arab. J. Sci. Eng., 33, 279 (2008).

17. J. Bošnir, D. Puntarić, A. Galić, I. Škes, T. Dijanić, M. Klarić, et al. Food. Technol. Biotechnol., 45, 91 (2007).

18. I. Kostić, T. Anđelković, D. Anđelković, A. Bojić, T. Cvetković, D. Pavlović, Bulg. Chem. Commun. 49, 360 (2017).

19. A. Fankhauser-Noti, K. Grob, Anal. Chim. Acta, 582, 353 (2007).

20. D. Milojković, D. Anđelković, G. Kocić, T. Andjelković, J. Serb. Chem. Soc., 80, 983 (2015).

21. Wisconsin Department of Natural Resources Laboratory Certification Program: Analytical Detection Limit Guidance \& Laboratory Guide for Determining Method Detection Limits, 1996. (http://dnr.wi.gov/regulations/labcert/documents/gui dance/-lodguide.pdf). 